\title{
Wintertime observations of Subtropical Mode Water formation within the Gulf Stream
}

\author{
Terrence M. Joyce, ${ }^{1}$ Leif N. Thomas, ${ }^{2}$ and Frank Bahr ${ }^{1}$ \\ Received 5 September 2008; revised 6 November 2008; accepted 20 November 2008; published 28 January 2009.
}

[1] We study the structure of Subtropical Mode Water (STMW) within the eastward-flowing Gulf Stream as it forms during strong winter cooling. Shipboard observations using SeaSoar and ADCP reveal that while active mixing by gravitational instabilities is common, large vertical and lateral shears of the Gulf Stream play a central role in determination of the modes of active mixing. Evidence is presented that low static stability and large vertical shear can combine to cause slantwise convection/symmetric instabilities, while the large anticyclonic shears to the south of the Gulf Stream core can cause low absolute vorticity and precondition the Ertel potential vorticity to be small and more susceptible to instabilities. The area of active mixing driven by surface forcing in the presences of shear occupies a swath $50-90 \mathrm{~km}$ wide immediately south of the Gulf Stream core at the northern edge of the Sargasso Sea. Citation: Joyce, T. M., L. N. Thomas, and F. Bahr (2009), Wintertime observations of Subtropical Mode Water formation within the Gulf Stream, Geophys. Res. Lett., 36, L02607, doi:10.1029/2008GL035918.

\section{Introduction}

[2] The Subtropical Mode Water of the North Atlantic Ocean is called Eighteen Degree Water (EDW) [Worthington, 1959]. Mode Waters are characterized by low potential vorticity $(\mathrm{PV})$ or thick layers of low stability. The traditional view of EDW formation is that it is a 1-D process, isolated from the Gulf Stream with buoyancy extraction from seasonal thermocline waters, uncovering the pre-existing reservoir of EDW [Warren, 1972]. Using historical hydrographic data, Kwon and Riser [2004] showed that the deepest wintertime mixed layers (MLs) of EDW were found immediately south of the GS, and the distribution of MLs was spatially variable along the GS axis. Our hypothesis is that substantial EDW formation is found within the anticyclonic flow of the Gulf Stream (GS), in the extreme north of the Sargasso Sea, and that vertical and lateral shears associated with the GS make this formation process decidedly non 1-D. This suggests a GS involvement in the formation; how this is achieved is what we hope to present in this report.

[3] The measurements were taken during the winter of 2007 aboard the R/V Knorr as part of the CLIMODE program [The CLIMODE Group, 2008]. Our primary data were collected with a SeaSoar system in which a winged,

\footnotetext{
${ }^{1}$ Department of Physical Oceanography, Woods Hole Oceanographic Institution, Woods Hole, Massachusetts, USA.

${ }^{2}$ Department of Environmental Earth System Science, Stanford University, Stanford, California, USA.
}

Copyright 2009 by the American Geophysical Union. 0094-8276/09/2008GL035918\$05.00 flyable, underwater unit was outfitted with dual SeaBird temperature and conductivity probes, and combined with a dissolved oxygen sensor, fluorometer, and a pressure sensor. The SeaSoar fish was at the end of $1000 \mathrm{~m}$ of cable of which $550 \mathrm{~m}$ were faired. On the cruise, the SeaSoar successfully 'flew' between $30 \mathrm{~m}$ and $450 \mathrm{~m}$ as it was towed behind the vessel at speeds of $3-4 \mathrm{~m} / \mathrm{s}$. Prior to averaging over 1 second intervals, the temperature data were lagged to be in phase with conductivity and further adjustments were made using laboratory calibrations of the sensors with final corrections made against shipboard CTD/bottle data (http://science. whoi.edu/users/seasoar/climode/web/proc_summary.txt). The undulating SeaSoar data were then spatially gridded using a Gaussian weighting with a spatial smoothing scale of $(1 \mathrm{~km})^{2}$ in along-track distance and $(5 \mathrm{~m})^{2}$ in the vertical. A $75 \mathrm{kHz}$ Ocean Surveyor ADCP system mounted in the hull of vessel was configured to produce ensemble averages of subsurface currents with a resolution of 5 minutes (ca. $1.2 \mathrm{~km}$ along-track during SeaSoar operations) and $16 \mathrm{~m}$ in the vertical. ADCP data were collected with UHDAS provided by the University of Hawaii and ship's gyro data corrected using a POS/MV (a 3-axis position and orientation measurement system). The two data sets (SeaSoar and ADCP) were aligned in the along-track direction by lagging the ADCP records using a constant time offset of $2.5 \mathrm{~min}$ (ca. 450 $600 \mathrm{~m})$ relative to the SeaSoar data.

[4] The location of the SeaSoar data used here is at the eastern end of the study area from near the end of leg 1 on the Knorr (Figure 1). During its progression downstream in February, the seasonal stratification above the EDW was eroded by strong air-sea exchange, and the new vintage of EDW began to form [The CLIMODE Group, 2008] (Figure S1 of the auxiliary material). ${ }^{1}$ The surface outcrop of the EDW layer is given roughly by the area between the 17.5 and $18.5^{\circ} \mathrm{C}$ isotherms and, according to Figure S1, had opened up into a broad area just at the point in which our SeaSoar measurements were made. Our measurements immediately followed a cold air outbreak over the region with peak heat fluxes of $1000 \mathrm{w} / \mathrm{m}^{2}$ on 20 February (J. Edson, personal communication, 2008). All of our sections are plotted using a stream coordinate system in which the origin is at the location of the maximum vertically-averaged current and oriented so that the cross-stream direction is normal to the flow and oriented towards the warm side of the front.

\section{Results}

[5] Because low PV is an essential property of Mode Waters, it will be convenient to express the vorticity field

\footnotetext{
${ }^{1}$ Auxiliary materials are available in the HTML. doi:10.1029/ 2008GL035918.
} 


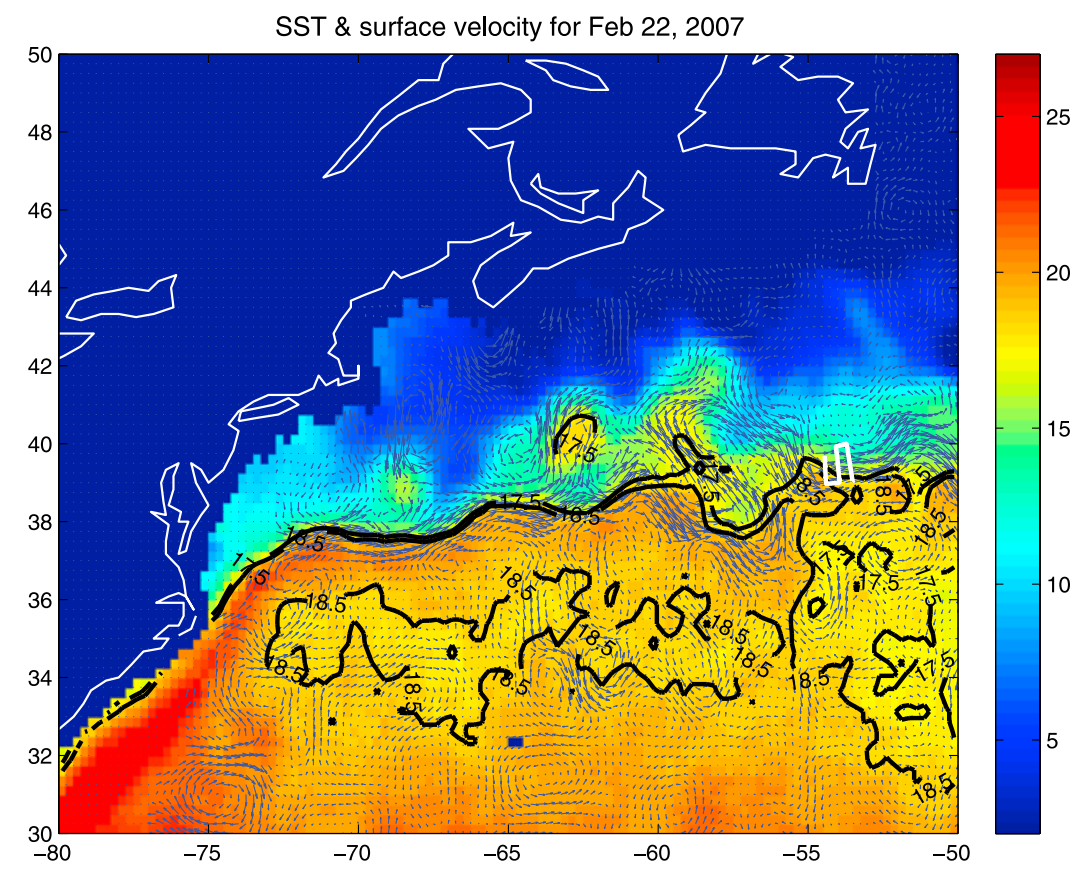

Figure 1. Microwave SST for 22 Feb. and altimeter SSH data for a 10 day period ending on this date were used, with assumptions about the mean SSH field. While at sea we used this information about SST and surface geostrophic flow (blue arrows), provided daily by Kathie Kelly from APL, UW, to plan various shipboard sampling, such as the SeaSoar survey (white lines) made at the opening or throat of the EDW outcrop, defined by the separation between the 17.5 and $18.5^{\circ} \mathrm{C} \mathrm{SST}$ isotherms.

near the Gulf Stream in terms of a 2-D Ertel Potential Vorticity, EPV

$$
\begin{gathered}
T_{1} \quad T_{2} \quad \begin{array}{lll}
T_{3} & T_{4}
\end{array} \\
E P V=(f+\zeta) N^{2}+\left(\gamma+V_{d z}\right)\left(g \rho_{x_{c}} / \rho_{0}\right), \text { or } \\
E P V=(f+\zeta) N^{2}-\left(\gamma+V_{d z}\right) f V_{d z}, \text { if geostrophic }
\end{gathered}
$$

where $f$ is the usual Coriolis parameter (vertical component of $2 \vec{\Omega}$ : twice the angular rotation vector of the earth), $\gamma$ is the northward component of $2 \vec{\Omega}$ projected along the crossfrontal coordinate, $x_{c}, \varsigma=v_{x}-u_{y} \approx V_{d x_{c}}$, is the vertical component of the relative vorticity expressed as the crossstream shear of the downstream velocity, $V_{d}$, and $V_{d z}, \rho_{x_{c}}$ represent the vertical shear of the downstream flow and cross-stream density gradient, respectively. We will denote the 4 terms in EPV as $T_{1} \ldots T_{4}$, as indicated in equation (1). Planetary $\mathrm{PV}, \mathrm{T}_{1}$, is generally taken to be the most important term in broad scale analyses; however this is not the case for sub-mesoscale flows whose Rossby and geostrophic Richardson numbers, $R i_{g}$, are order one [Thomas et al., $2008]$.

[6] The SeaSoar/ADCP section (Figure 2) reveals a strong front demarking the north wall of the Gulf Stream near the 'origin' of our coordinate system. Near this location there are large horizontal gradients of density. For negative crossstream values, we see colder, more oxygenated waters. Near the surface at the extreme left of the sections (e.g., Figure 2c), one can see that the SeaSoar was unable to sample and thus, there are no gridded data produced. Water being actively mixed as a result of the intense surface forcing can be seen by the inversions of density (Figure 3a), but more prominently in regions of negative EPV (Figure 3c). Ullman et al. [2003] point out that use of SeaSoar, which takes sloping trajectory through the water, can cause erroneous density inversions when the slope of the path is $<0.1$. For most of our section, the slope was 0.4 , with only a small region within $20 \mathrm{~m}$ of the upper and lower limits of the SeaSoar path with slopes of 0.1 . Two distinct 'flavors' of low EPV waters can be seen here: a cold subpolar mode water with a temperature of ca. $13^{\circ} \mathrm{C}$ to the north of the front, and subtropical mode water or EDW to the south. These two mode waters have high values of oxygen, as estimated by $\%$ oxygen saturation (Figure 3b) and fluorescence (Figure 3d), but have substantially different salinities (see Figure S1).

[7] What is clear in comparing the EPV and the 1-D estimate from term T1 $\left(f N^{2}\right)$ is that there are a substantial number of regions with negative EPV below $100 \mathrm{~m}$ depth that are not suggested by the stratification alone; and these are organized spatially. To see how vertical and lateral shear produce these low EPV regions, we calculate a simple diagnostic by taking the vertical average of all the relevant terms between depths of 100:300 m (Figure 4). There is a region of low static stability near $\mathrm{x}_{\mathrm{c}} \sim 18 \mathrm{~km}$, which can also be seen in Figure $3 \mathrm{a}$. There are two regions where EPV is near zero that are associated with large anticyclonic shear at $\mathrm{x}_{\mathrm{c}} \sim 10,32 \mathrm{~km}$ (Figure 4c). At these locations, the absolute vorticity approaches zero. At $\mathrm{x}_{\mathrm{c}} \sim 27,51 \mathrm{~km}$, high vertical shears, reflected in low geostrophic Richarson numbers (Figure 4c) and positive downstream vertical shear (Figure 4b) account for two other regions of low EPV. Note that regions of large lateral shear and vertical shear are not found together. The association of low EPV values with 

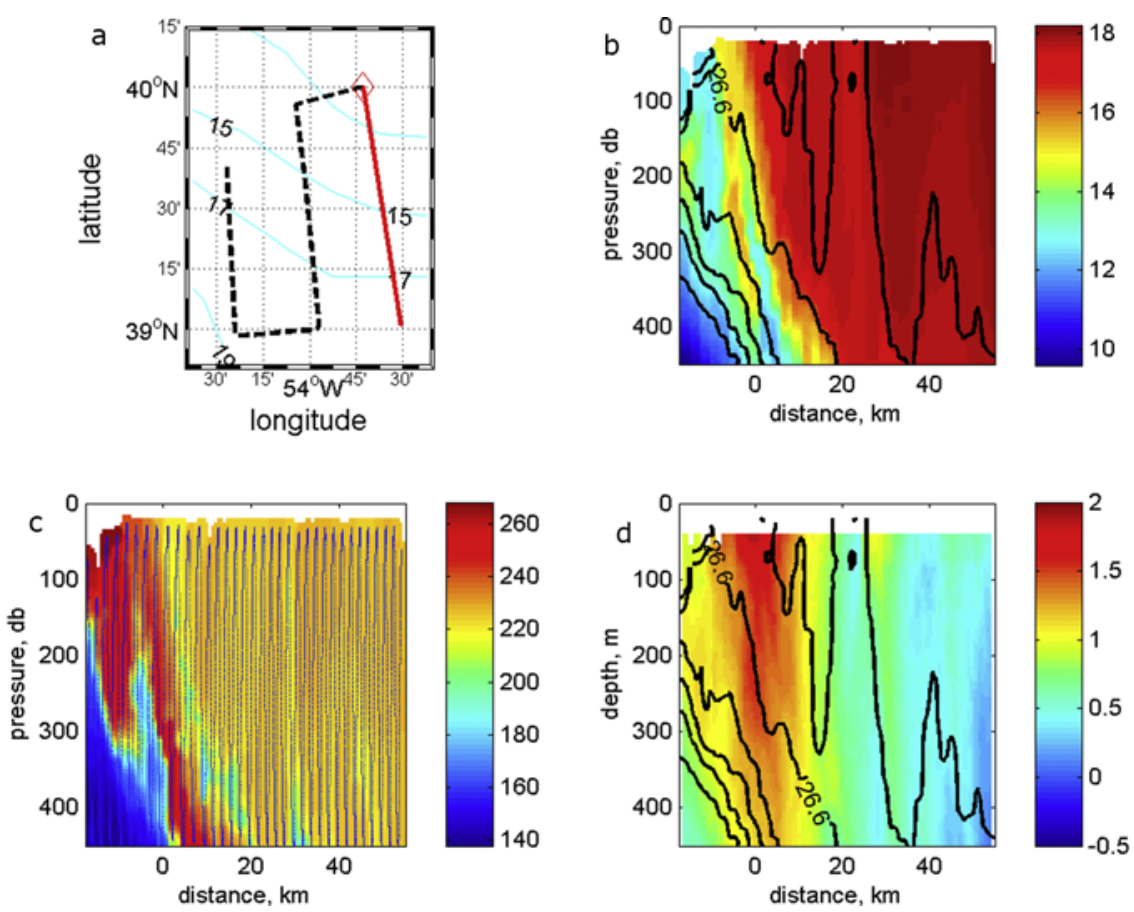

Figure 2. (a) The third line of the SeaSoar survey (red) is used for cross-frontal display of some basic variable such as (b) potential temperature $\left({ }^{\circ} \mathrm{C}\right)$, (c) dissolved oxygen $(\mu \mathrm{mole} / \mathrm{kg})$, and $(\mathrm{d})$ downstream velocity $(\mathrm{m} / \mathrm{s})$. The oxygen section has the track of the SeaSoar superimposed (black dots). The beginning location of each section is given by the red diamond (Figure 1a).
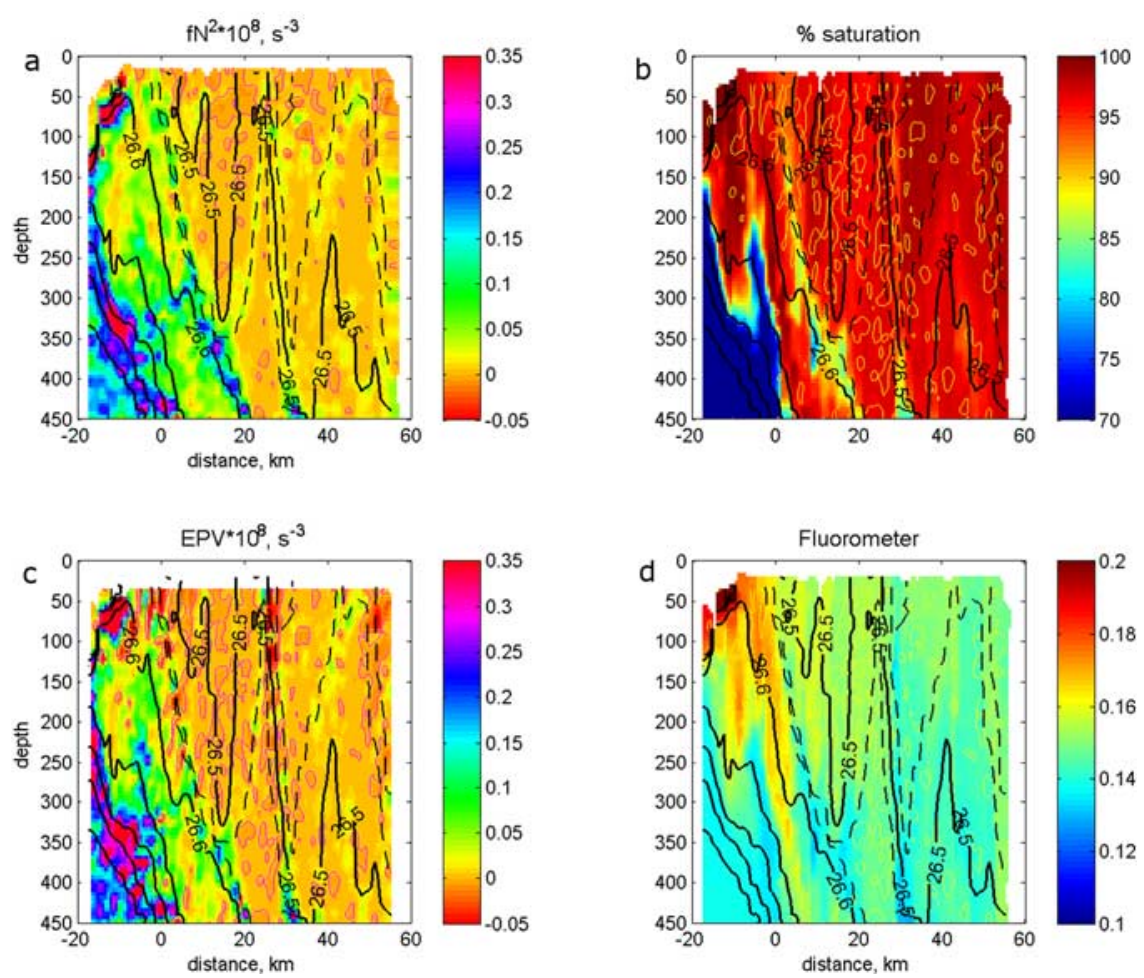

Figure 3. As in the previous figure, the stratification term, (a) T1 is shown with selected potential density contours superimposed (black contours, dashed contours are for $\sigma_{\theta}=26.46,48.52$, and 54). Regions of negative static stability are shown as thin magenta lines. (b) The \% saturation of dissolved oxygen is the ratio of the observed oxygen to that for a fully saturated water parcel with the same properties as that observed. (c) The 2-D EPV, defined in equation (1) shows substantial regions where EPV $<0$ (thin magenta or yellow lines), yet the stratification is stable. (d) Chlorophyll fluorescence as measured by an uncalibrated fluorometer on the SeaSoar shows large variations with high fluorescence usually associated with high oxygen saturation and negative EPV. 

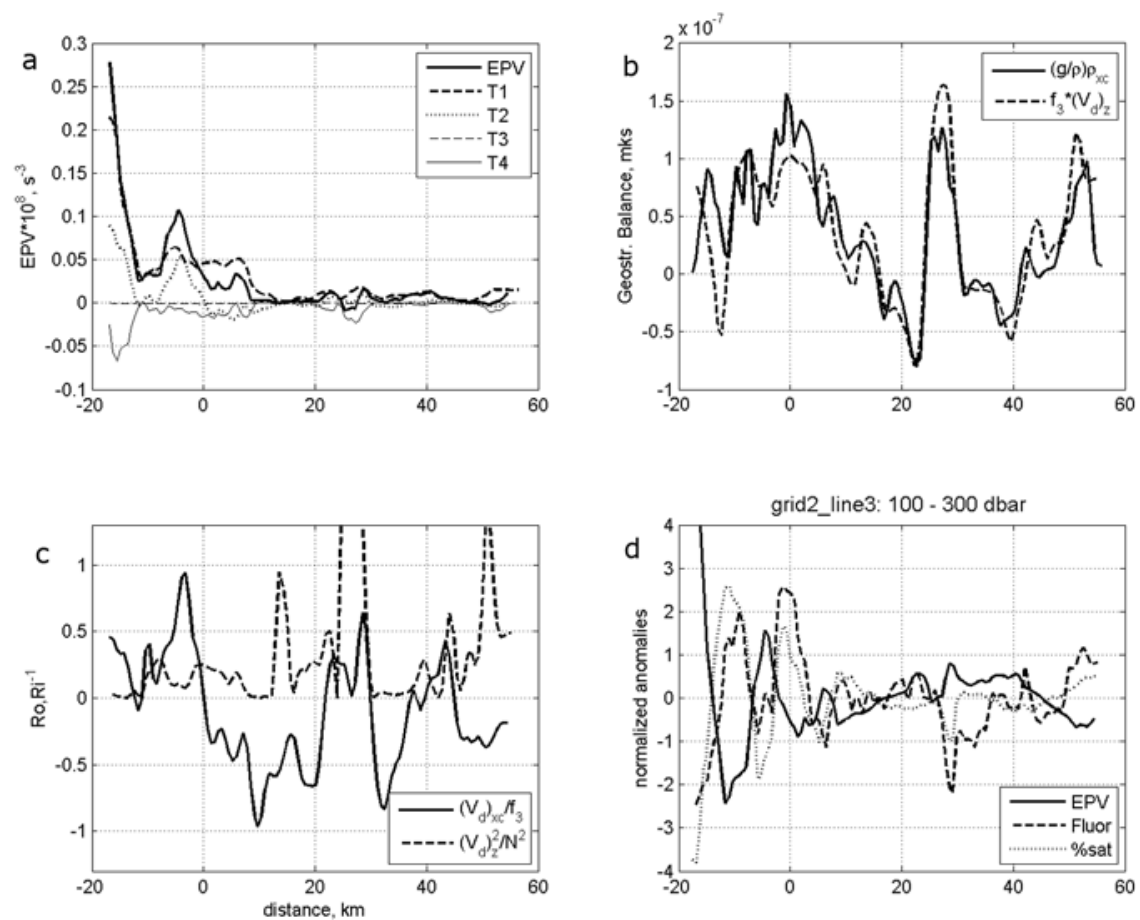

Figure 4. (a) The various terms in the EPV balance equation (1) are averaged vertically between 100:300 m depth. The two terms in the geostrophic balance are shown at the upper right. (b) The Rossby number ( $\varsigma$ ), and (c) inverse geostrophic Richardson number $\left(N^{2} / V_{d z}^{2}\right)^{-1}$ denote regions of large lateral and vertical shear, respectively, which are associated with regions of low EPV. (d) Anomalies of EPV, fluorescence, and dissolved oxygen, after taking departures from a smooth polynomial fit for each variable in the cross-stream direction.

high relative values of oxygen and fluorescence (lower right) is supportive of the hypothesis that low EPV values signify active mixing or subduction and recent contact with the surface.

[8] Analysis of regions of negative EPV (Figure S2) shows that the actively mixing regions occupy a dominant density class of $26.5 \mathrm{~kg} / \mathrm{m}^{3}$, which is newly-forming EDW. In physical space, this new EDW is found nearly everywhere on the section (Figure 3c) above the strongly-sloping 26.6 isopycnal. Mode water found below this surface in the density range $26.6: 26.7 \mathrm{~kg} / \mathrm{m}^{3}$ is being exported from the cold side of the front. We diagnose the contribution of the different terms in the EPV starting with the stratification, $\mathrm{T}_{1}$, and then adding the effect of vertical shear $\left(\mathrm{T}_{4}\right)$ and then lateral shear $\left(\mathrm{T}_{2}\right)$. For this particular 'section, there are few regions of negative EPV that are solely due to density inversions $(<5 \%)$, but inclusion of vertical shear accounts for most $(>90 \%)$. Generally, the lateral shear term, $\mathrm{T}_{2}$, is significant in regions of large anticyclonic vorticity, and the remaining term $T_{3}$ accounts for little on this section. The coincidence of low EPV, constant potential density and high fluorescence/oxygen following the sloping 26.46 and 26.48 isopycals (dashed, Figure 3) downward from the surface at $\mathrm{x}_{\mathrm{c}} \sim 51 \mathrm{~km}$, where $R i_{g} \sim 1$, is an oceanic example of slantwise convection/symmetric instability. In the auxiliary material (Figure S3) we show the absolute momentum surfaces for this section, which also parallel these other indicators of descending, recently-ventilated fluid at this site. While not as clearly-resolved as what has been observed in the atmosphere [e.g., Emanuel, 1988], we believe this is a graphic example of slantwise convection/symmetric instability in the ocean. A similar feature at $\mathrm{x}_{\mathrm{c}} \sim 27 \mathrm{~km}$ is also present but is not as graphically isolated.

\section{Discussion}

[9] First evidence for the role of vertical and lateral shear in defining occurrence of low EPV in the ocean [Hua et al., 1997] was made for the equatorial band, where the existence of low EPV was assured without strong surface forcing. There the northward component of the Coriolis parameter played an important role in balancing vertical shear for depths below the thermocline. We have retained this term in our analysis, but generally, it is of little significance compared with the other terms in (1). Slantwise convection was speculated to be active in the Labrador Sea [Straneo et al., 2002], but no observational evidence in the region has yet emerged. Here we show that in the upper ocean near the GS, term $\mathrm{T}_{4}$ can play an important contribution at reducing the EPV. Another mid-latitude front where this has been seen is the subpolar front of the Japan/East Sea where regions with negative EPV yet stable stratification were found [Thomas and Lee, 2005]. Both our observations and those at the subpolar front of the Japan/ East Sea were made during and after cold air outbreaks characterized by intense heat loss and strong wind-stress [Lee et al., 2006], suggesting that the low EPV water observed at the fronts was a consequence of the atmospheric forcing experienced at the fronts. It is not surprising that heat loss can generate low EPV water but wind-driven frictional forces can also reduce the EPV if the winds have a component directed along the frontal jet [Thomas, 2005]. 
Both of these effects are likely to have influenced the formation of the low EPV water that we observed in the GS.

[10] Ertel Potential Vorticity (EPV) is a dynamical variable which more clearly documents formation/ventilation of EDW than planetary potential vorticity, $f N^{2}$. We associate recently formed EDW with waters with near zero or negative values of the EPV that lie in the EDW density class. Fluid with negative EPV is expected to be unstable to gravitational, symmetric, or inertial instability owing to the effects of static instability, large vertical shears, and large lateral shears, respectively [Hoskins, 1974; Haine and Marshall, 1998]. We expect that all three processes are active in the GS during EDW formation. Numerical simulations of ocean fronts forced by winds that develop frontal flow with negative EPV show that this mixing process is effective at exchanging water from the near surface with water from the pycnocline [Thomas, 2005, 2008]. In our observations of the GS, the use of low EPV water as an indicator of active vertical exchange is born out by the enhanced levels of dissolved oxygen ( $>95 \%$ saturated) and high chlorophyll fluorescence, both of which indicate recent export from the near surface region where there are strong sources for each. Our observations indicate that active EDW formation occurs throughout a swath immediately to the south of the GS front, in a region 50-90 km wide in which both vertical and lateral shears of the GS play key roles in lowering the EPV.

[11] Convective mixing within the Gulf Stream necessarily precludes any simple 1-D interpretation: we have used a 2-D analysis in stream coordinates, which assumes that major flows are downstream and that major variations in the flow occur at right angles, in the cross-stream direction. Having multiple crossing of the Gulf Stream with the shipboard ADCP and SeaSoar, we can see that these assumptions are valid in general. In this region, our SeaSoar, which was limited to depths $<450 \mathrm{~m}$, often did not penetrate to the bottom of the surface mixing layer, which extended up to $500 \mathrm{~m}$ based on CTD measurements.

[12] Inspection of the terms in EPV (1) indicates that the important vertical shear term is a non-linear product of vertical shear and horizontal density gradient. This mechanism for lowering EPV is a maximum for perfectly correlated, geostrophic flows, and smaller (in the mean) for completely ageostrophic flows. Our example here is dominantly geostrophic, but there are other instances in CLIMODE where large near inertial oscillations are present and vertical shears are ageostrophic. These strong inertial (actually slightly subinertial) oscillations [The CLIMODE Group, 2008] are effectively trapped by the anticyclonic vorticity field in the same region of the GS that we are sampling here: namely where EDW first appears on the Sargasso Sea side of the GS.

[13] Acknowledgments. During the period of our SeaSoar survey, the $\mathrm{R} / \mathrm{V}$ Knorr was repeatedly crossing the Gulf Stream, with both the strong flow $(0-2 \mathrm{~m} / \mathrm{s})$ and the persistent winds (and seas) of up to $16-17 \mathrm{~m} / \mathrm{s}$ crossing our beam. Yet the skill of the bridge and their ability to use dynamic positioning made our actual SeaSoar lines look like the ones drawn on a map BEFORE the sections were done. We also wish to acknowledge support of those on shore who provided us timely satellite and weather data during the cruise. This work was part of CLIMODE (www.climode.org), a process study of US CLIVAR. Support came from the National Science Foundation grants OCE-0424865 (TJ and FB) and OCE-0549699 (LT).

\section{References}

Emanuel, K. A. (1988), Observational evidence of slantwise convective adjustment, Mon. Weather Rev., 116, 1805-1816.

Haine, T. W. N., and J. Marshall (1998), Gravitational, symmetric, and baroclinic instability of the ocean mixed layer, J. Phys. Oceanogr., 28, $634-658$.

Hoskins, B. J. (1974), The role of potential vorticity in symmetric stability and instability, Q. J. R. Meteorol. Soc., 100, 480-482.

Hua, B. L., D. W. Moore, and S. Le Gentil (1997), Inertial nonlinear equilibration of equatorial flows, J. Fluid Mech., 331, 345-371.

Kwon, Y.-O., and S. C. Riser (2004), North Atlantic Subtropical Mode Water: A history of ocean-atmosphere interaction 1961-2000, Geophys. Res. Lett., 31, L19307, doi:10.1029/2004GL021116.

Lee, C. M., L. N. Thomas, and Y. Yoshikawa (2006), Intermediate water formation at the Japan/East Sea subpolar front, Oceanography, $19,110-121$

Straneo, F., M. Kawase, and S. C. Riser (2002), Idealized models of slantwise convection in a baroclinic flow, J. Phys. Oceanogr., 32, 558-572.

The CLIMODE Group (2008), Observing the cycle of convection and restratification over the Gulf Stream system and the subtropical gyre of the North Atlantic ocean: Preliminary results from the CLIMODE field campaign, Bull. Am. Meteorol. Soc., in press.

Thomas, L. N. (2005), Destruction of potential vorticity by winds, J. Phys. Oceanogr., 35, 2457-2466.

Thomas, L. N. (2008), Formation on intrathermocline eddies at ocean fronts by wind-driven destruction of potential vorticity, Dyn. Oceans Atmos., $45,252-273$.

Thomas, L. N., and C. M. Lee (2005), Intensification of ocean fronts by down-front winds, J. Phys. Oceanogr., 35, 1086-1102.

Thomas, L. N., A. Tandon, and A. Mahadevan (2008), Submesoscale processes and dynamics, edited by M. Hecht and H. Hasumi, in Ocean Modeling in an Eddying Regime, Geophys. Monogr. Ser., 177, 17-38, AGU, Washington, D. C.

Ullman, D. S., A. C. Dale, D. Hebert, and J. A. Barth (2003), The front on the Northern Flank of Georges Bank in spring: 2. Cross-frontal fluxes and mixing, J. Geophys. Res., 108(C11), 8010, doi:10.1029/2002JC001328.

Warren, B. A. (1972), Insensitivity of subtropical mode water characteristics to meteorological fluctuations, Deep Sea Res., 19, 1-19.

Worthington, L. V. (1959), The $18^{\circ}$ water in the Sargasso Sea, Deep Sea Res., 5, 297-305.

F. Bahr and T. M. Joyce, Department of Physical Oceanography, Woods Hole Oceanographic Institution, MS 21, 360 Woods Hole Road, Woods Hole, MA 02543, USA. (tjoyce@whoi.edu)

L. N. Thomas, Department of Environmental Earth System Science, Stanford University, 473 Via Ortega, Stanford, CA 94304, USA. 